\title{
Space deficits in Parkinson's disease patients: quantitative or qualitative differences from normal controls?
}

\author{
D. Natsopoulos', M.-S. Bostantzopoulou'2, Z. Katsarou², G. Grouios ${ }^{3}$ \\ and G. Mentenopoulos ${ }^{2}$
}
${ }^{1}$ Psychology Department, ${ }^{2} B$ Neurological Clinic, AHEPA Hospital, and ${ }^{3}$ Department of Physical Education, University of Thessaloniki, Greece

Correspondence to: D. Natsopoulos, Psychology Department, University of Thessaloniki, Thessaloniki 54006, Greece

\begin{abstract}
Twenty-seven patients with idiopathic Parkinson's disease (PD) and the same number of normal controls (NCs) were studied on a test battery including five conceptual categories of spatial ability. The two groups of subjects were matched for age, sex, years of education, socioeconomic status and non-verbal (Raven Standard Progressive Matrices) intelligence. A multivariate analysis of variance (MANOVA) showed that the PD patients performed less efficiently on almost all the tasks. A logistic regression analysis (LRA) classified $81.48 \%$ of the subjects into the PD group and $92.59 \%$ into NC group, indicating that left-right and back-front Euclidean orientation, three dimensional mental rotation and visuospatial immediate recognition memory of mirror image patterns discriminate well between the two groups. Application of a structural model (confirmatory factor analysis) demonstrated that both PD patients and the NC group stemmed from a homogeneous population, suggesting that the differences found between the two groups are of a quantitative rather than of a qualitative nature.
\end{abstract}

Keywords: Parkinson's disease - Qualitative differences - Quantitative differences - Space deficits

\section{INTRODUCTION}

Cognitive impairment in patients with Parkinson's disease (PD) has been the focus of intensive research over the past two decades. This research covers a wide spectrum of impairment of cognitive functions comprising specific aspects of language, like syntax (Illes et al., 1988; Illes, 1989; Lieberman et al., 1990, 1992; Lieberman, 1991; Natsopoulos et al., 1991 a, b, 1993; Grossman et al., 1991, 1992, 1993); verbal memory (Sagar et al., 1988a, b; Breen, 1993; Cooper and Sagar, 1993); spatial and/or visuospatial memory (Pirozzolo et al., 1982; Boller et al., 1984; Globus et al., 1985; Huber et al., 1986; Hietanen and Teräväinen, 1988; Sahakian et al., 1988; Bradley et al., 1989; Levin et al., 1989; Ogden et al., 1990; Adelstein et al., 1992; Owen et al., 1993); spatial ability, spatial orientation and visuoconstructive aptness (Pirozzolo et al., 1982; Boller et al., 1984; Globus et al., 1985; Goldenberg et al., 1986; Huber et al., 1986; Hovestadt et al., 1987; Brown and Marsden, 1988; Gotham et al., 1988; Hietanen and Teräväinen, 1988; Levin et al., 1989; 1991; Ogden et al., 1990; Testa et al., 1993); attention shifts and alternation conceptual sets (Lees and Smith, 1983; Flowers and Robertson, 1985; Taylor et al., 1986; Mohr et al., 1987; Brown and Marsden, 1988; Gotham et al., 1988; Caltagirone et al., 1989;
Sharpe, 1990a; Wallesch et al., 1990); problem solving, reasoning and numerical ability (Brown et al., 1984; Channon et al., 1993).

In contrast to findings showing that $\mathrm{PD}$ patients perform less well than normal controls on tasks requiring abilities such as the ones mentioned, other data indicate that PD patients do as well as normal subjects on tests demanding verbal memory (Lees and Smith, 1983; Flowers et al., 1984; Goldenberg et al., 1986; Taylor et al., 1986; Bradley et al., 1989) and/or spatial memory capacity (Flowers et al., 1984; Bradley et al., 1989; Owen et al., 1993); spatial and visuospatial ability, mental rotation and orientation (Brown and Marsden, 1986; Della Sala et al., 1986; Goldenberg et al., 1986; Taylor et al., 1986; Levin et al., 1989; Ogden et al., 1990); visuospatial attention and conceptual shifting (Rafal et al., 1984; Levin et al., 1989; Stelmach et al., 1989; Sharpe, 1990b) and spatial problem solving Morris et al., 1988; Wallesch et al., 1990; Channon et al., 1993).

Previous reviews of the relevant research reveal more or less the same pattern: PD patients are 62\% and 63\% "visuospatially impaired" (Bradley et al., 1989; Stelmach et al., 1989, respectively); 50\% "visuospatially and visuo- 
perceptually impaired" according to Brown and Marsden (1986), whereas $28 \%$ of them show "pervasive cognitive changes", $36 \%$ suffer "specific cognitive deficits" and $36 \%$ display "no significant mental deterioration" (Taylor et al., 1986).

With regard to variables affecting cognitive impairment in PD, the picture is also not unequivocal. Thus, depression affects cognitive performance according to some investigators (Starkstein et al., 1989) but not to others (Mortimer et al., 1982; Boller et al., 1984; Sharpe, 1990b; Channon et al., 1993); affect/arousal status is associated with cognitive performance (Brown et al., 1984) or it is independent of mood (Sharpe, 1990a); age itself is not related to cognitive impairment (Brown et al., 1984; Flowers et al., 1984; Hovestadt et al., 1987; Levin et al., 1991), whereas the same variable plays a significant role for others (Flowers and Robertson, 1985; Hietanen and Teräväinen, 1988).

These conflicting results can be attributed to various methodological approaches and even to methodological shortcomings, according to Gotham et al. (1988), Sagar (1991) and Taylor et al. (1986).

What is of paramount importance is the evidence suggesting that cognitive impairment in the form of spatial ability is independent of intelligence (Lees and Smith, 1983; Boller et al., 1984; Brown et al., 1984; Brown and Marsden, 1986; Taylor et al., 1986; Caltagirone et al., 1989; Sharpe, 1990a). The implications drawn from this evidence are interesting for theoretical and diagnosticpractical purposes.

The present study was designed to explore the first part of the previous assertion, i.e. spatial ability in PD, for the following reasons. Very few studies (cf. Lees and Smith, 1983; Morris et al., 1988; Bradley et al., 1989) matched non-verbal intelligence in PD patients and controls. Subsequently, strict control of the non-verbal intelligence effect may provide a different picture from that emerging from the reviewed studies. Further, a conceptual rather than an operational basis for task selection is needed in studying spatial ability in PD patients (cf. Mortimer et al., 1982, p. 134; Pirozzolo et al., 1982, p. 76; Boller et al., 1984, p. 488; Taylor et al., 1986, pp. 856-857 for an exception), because spatial ability is not a unidimensional entity as has been widely acknowledged (cf. especially De Renzi, 1982; Levin, 1990). Also, testing left side lateralized effect versus right side (cf. Taylor et al., 1986) may differentiate existing subgroups within the PD continuum. The evidence accumulated so far suggests that involvement of the left hemisphere in the spatial and/or visuospatial processing is particularly important in normal and pathological cases (cf. reviews by De Renzi, 1982; Kosslyn, 1987; Andersen, 1988; Morrow and Ratcliff, 1988; Mehta and Newcombe, 1991; Pigott and Milner, 1993, among others). Frontal lobe involvement in verbal and/or spatial function has also been implicated by convergent evidence in PD patients (Lees and Smith, 1983; Cools et al., 1984; Taylor et al., 1986; Brown and Marsden, 1988).

On methodological grounds using more sensitive techniques of data analysis (i.e. logistic regression analysis and confirmatory factor analysis) one may judge whether PD patients as a group are distinctly different from controls on the basis of the most sensitive task performance, and whether group membership necessarily implies qualitative differences and/or non-homogeneity of the population from which the two samples result. Finding differences in PD and controls merely in terms of mean differences does not necessarily reveal specific deficits discriminating reliably between the groups in space ability.

The aim of this study was to investigate differences in space ability between PD patients and controls by advancing the following predictions:

(1) If self-generated strategies for planning and organizing behaviour necessitate frontal lobe involvement (cf. particularly Lees and Smith, 1983; Cools et al., 1984; Taylor et al., 1986; Brown and Marsden 1988), block design (BLD), picture arrangement (PA) and object assembly (OA) tasks (Wechsler, 1955) would, ceteris paribus, discriminate between $\mathrm{PD}$ patients and normal control subjects (NCs) because these tasks are assumed to tap such frontal lobe function at input flow.

(2) If control of attention operating differentiates PD patients from NCs according to Brown and Marsden's (1988) reasoning, one would also assume that matching of visuoperceptually generated patterns would place differential demands for PD and NC subjects under relative time restrictions with tasks such as picture completion (PC; Wechsler, 1955) and closure of geometric figures (CGF; cf. description in the following section).

(3) (a) If left-right orientation, associated with the posterior parietal cortex is not impaired in PD patients (Brown and Marsden, 1986, p. 999; Taylor et al., 1986, p. 857) and spatial reasoning is not dependent upon the processing of allocentric (extrapersonal) stimuli (Taylor et al., 1986, p. 857), one may assume that left-right, back-front orientation (MR; part A) and mental rotation (part $B$ ) untimed tasks which demand coordination of extrapersonal (allocentric) perspectives would, mutatis mutandis, show similar behaviour with PD and NC subjects.

(b) In contrast, timed tasks such as the geometric embedded figures (GEF), implicating also posterior parietal cortex (Taylor et al., 1986, p. 857) and requiring visual discrimination of rival patterns, alternating of spatial set and/or figure-ground relationships, may discriminate between PD patients and NCs as a result 
of differential involvement of the posterior parietal cortex due to "influence of basal ganglia dysfunction on motor cortical areas" (Taylor et al., 1986, p. 856) displayed by patients during tracing the embedded figure in hand.

(4) Immediate memory of visuospatial patterns in right temporal lesioned individuals is as well preserved as in left, and frontal lobe excisioned and control subjects, suggesting that encoding and retention or retrieval of visuospatial information is equally efficient (Piggott and Milner, 1993, p. 11; cf. also Smith and Milner, 1981, 1989). By extrapolation, PD patients may display no impairment of immediate visuospatial memory in recognition of mirror image space patterns on homologous tasks (i.e. VSM).

(5) (a) Studying left versus right side lateralized effect in PD patients on a broad range of spatial cognition tasks may reveal specific differences in the modular organization of the two hemispheres as other data in patients with focal lesions suggest (Mehta et al., 1987; Mehta and Newcombe, 1991; cf. also an extensive review by Kosslyn, 1987).

(b) Disease duration (DD) with age, disease stage (DS) and intelligence controlled may also reveal the existence of subgroups along the PD continuum.

\section{METHODS}

\section{Subjects}

Twenty-seven patients with clinically idiopathic PD and 27 NCs were tested in this study. The PD patients were recruited from the population of the out-patient unit for Parkinson's disease at Agios Dimitrios Hospital in the city of Thessaloniki, Greece, according to the following criteria: age $($ mean $=58.55$ years; S.D. $=7.51$ years; age range 47-69 years); education (6 years primary school); absence of dementia (cf. DSM-III, APA, 1980); perform- ance on the Mini-Mental State Examination (MMSE; mean $=29.11$; S.D. $=1.24$; score range 27-30; Folstein et al., 1975; Folstein, 1983); absence of severe depression and concomitant metabolic or endocrine disorders. The PD patients were examined independently by two neurologists, co-authors of the study (S.B. and Z.K.), and the clinical symptoms of the disease were rated according to the Unified Parkinson's Disease Rating Scale (Fahn et al., 1987). They were also classified by stage of the disease by means of the modified Hoehn and Yahr Classification Scale (Hoehn and Yahr, 1967). The rate of concordance concerning neurological examination between the two independent examiners was $90 \%$. The clinical characteristics of the PD patients are presented in Table I. Ten of the PD sample were females. Two of the patients, one male and one female, were left handed. None of the subjects had participated in a similar experiment before.

The NC subjects matched the PD patients on age, education, non-verbal intelligence [on C, D, E groups of 36 items on Raven's Standard Progressive Matrices (RSPM); Raven, 1958]; sex; socioeconomic status (SES) and handedness. As with PD patients, the NC subjects had no previous experience with this sort of testing. Table II displays the matching variables for PD and NC subjects.

\section{Psychological testing}

A battery of eight spatial tasks were presented to the subjects to assess spatial ability in PD patients and NCs. Four of the eight tasks were Wechsler's (Wechsler, 1955) BLD, OA, PA and PC. Two of the tasks, CGF and VSM, were designed by the first author (D.N.); the GEF task was adopted from Feuerstein (1980), and the MR task consisted of two parts, one also adopted from Feuerstein (1980) and the other designed by the first author (D.N.).

Although it is widely admitted that space ability encompasses a broad range of cognitive functions requiring a wide spectrum of abilities, the tasks which were used

TABLE I. Clinical characteristics of the PD patients

\begin{tabular}{lccc}
\hline & Number & Mean & S.D. \\
\hline Females & 10 & & \\
Males & 17 & & \\
Duration of the disease & & 6.07 years & 3.32 \\
Stage & & 2.50 years & 0.42 \\
Cardinal symptoms scoring (0-4) & & \\
$\quad$ rremor & & 1.00 & 0.54 \\
$\quad$ Rigidity & & 1.37 & 0.62 \\
$\quad$ Bradykinesia & & 1.55 & 0.69 \\
$\quad$ Treatment & & & \\
$\quad$ Levodopa and/or agonists & 20 & & \\
$\quad$ Levodopa, agonists and anticholinergics & 6 & & \\
$\quad$ Without treatment & 1 & & \\
\hline
\end{tabular}


TABLE II. Matching variables of the PD patients and NC subjects

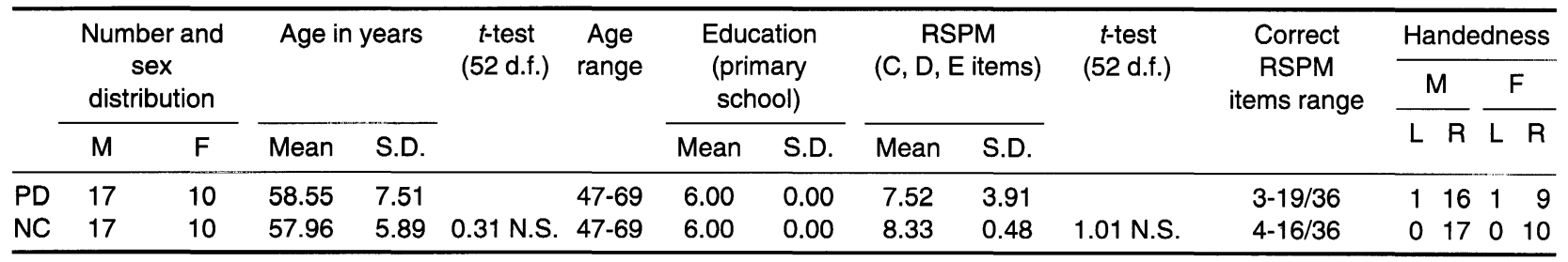

in this study seem to fit with a set of conceptual space categories suggested by some researchers (cf. especially De Renzi, 1982; Ratcliff, 1982; Kritchevsky, 1988; Levin, 1990).

In line with the previous studies, it was assumed that the BLD, OA and PA tasks have strong affinities with "constructional praxis", an ability that requires formation of a single entity by putting together separate items. The PC and CGF tasks call for a sustained visuoperceptual attention and scanning to overcome a likely mismatch during the stimuli process. The MR task (part A) requires leftright, back-front orientation of a Euclidean nature and taking extrapersonal perspectives. The second part of the task (part B) demands coordination of extrapersonal perspectives and mental rotation with regard to relationships of moving versus steady three-dimensional stimuli. The GEF task demands shifting set between perceptually competing geometric figures or figure-ground relationships and the VSM task requires a detailed visual analysis and memory of mirror image space patterns.

Description of the MR, CGF, VSM and GEF tasks. The MR task consisted of two subtasks: the first included a red circle made of cardboard of $12 \mathrm{~cm}$ radius with four toy observers placed on the four points on the circumference, determined by the two crossed diameters (quadrants). The circle was adjusted to a large $35 \times 35 \mathrm{~cm}$ square made of white cardboard. Two toy racing cars, one yellow with a black star on the left side and a black arrow on the right, and one red car with a white arrow on the left side and white star on the right, formed the first part of the MR task apparatus. The second part of the MR task consisted of four two-dimensional human figures (a man, a child, a woman and a girl) who were front, back, left and right facing the observer, respectively, and of a house facing the observer, with a bench to the left of the house, a garden with flowers facing the house, and a tree to the right of the house with regard to the observer's perspective. The CGF task stimuli included three series, one of six black trapezoids, one of six red circles and one of six red stars, all made of cardboard. All figures were cut down by a fixed ratio and formed progressively a sequence ranging from a full trapezoid, full circle or full star to the smallest part (portion) of a trapezoid and the smallest arc and the smallest part of a star, respectively. The VSM task comprised 20 series of geometric figures varying in complexity with five items each. One of the most complex figures was the target stimulus to which the subjects were briefly exposed before the recognition phase started. The target stimulus consisted of two pairs of geometric figures, each the mirror image of the other. Of the remaining four, one was identical to the target stimulus and three had similar or different features to the target stimulus. The GEF included five sets of geometric figures, one consisting of three ellipses, one of three circles, one of two parallelograms combined with one trapezoid, one of two orthogonal parallelograms and one of two triangles, respectively. The figures crossed each other in such a fashion that from each set a large number of figures of varying form and complexity resulted. Samples of the MR, CGF, VSM and GEF task series are presented in the Appendix.

Procedure. The eight tasks were administered to the subjects individually by D.N. and G.G. after the experimental procedure had been standardized. The PD patients were tested at Agios Dimitrios Hospital in a comfortable room following their neurological assessment by two experienced neurologists (S.B. and Z.K., see Methods). The NCs were tested at their homes after informed consent was obtained. The whole testing session including the administration of RSPM (see Methods) lasted 90-100 min for the PD patients and 75-85 min for the NC subjects.

The order of administration of the eight tasks was the same for all subjects with Wechsler's tests always presented first. The Wechsler's PC, BLD, PA and OA tasks were administered according to the instructions in the manual (Wechsler, 1955) with a slight modification, i.e. the time restrictions were less stringent, but uniformly observed for all subjects. The MR task was untimed for either subtask. On subtask A, the subject was asked to predict which side (star or arrow for the yellow race car and arrow or star for the red race car) each observer would face when both cars were racing in front of them. The experimenter had first placed the two toy cars in the distance between observer A and observer B on the circumference, with the yellow toy car displaying the star on the left side and the arrow on its right side and the red toy car displaying the arrow on its left side and the star on its right side. 
The subject was then told to predict, without moving the cars, which side of the two cars would appear to observer $B$ and observer D;C and A; D and B and A and C at the same time when the two toy cars were racing in front of the observers. On subtask B of the MR task the subject was asked to name which of the four stimuli (i.e. the house, the garden, the tree and the bench) would be to the front, to the back, to the left and to the right with regard to the four figures, i.e. to the man, to the child, to the woman and to the girl when facing the testee, the house, the bench and the tree, respectively. On the CGF task, the subject was instructed to place the geometric figures in order from the smallest to the largest, or vice versa, within a period of $20 \mathrm{~s}$ for each figure test. The VSM task was administered as follows: the subject was allowed to inspect the complex geometric target stimulus for $10 \mathrm{~s}$ (exposure phase) in any preferred orientation. After the target stimulus had been removed, the experimenter placed the four geometric figures in front of the testee at random positions and orientations, and she or he was given $10 \mathrm{~s}$ to select the figure that was identical to the one shown during the exposure phase. With regard to the GEF task, the subject had to number as many figures as she or he could within $60 \mathrm{~s}$ on each of the five sets, by following the drawn figures with a pencil, while observed by two experimenters (G.G. and D.N.) to make sure that no figure was calculated twice.

Scoring. The raw score, theoretical minimum to maximum on each individual task and/or subtask, was as follows: PC, 0-21; BLD, 0-48; PA, 0-36; OA, 0-44. The scoring (unscaled) on PC, BLD and OA complied with the WAIS manual (Wechsler, 1955) regarding time bonus for those subjects who happened to perform within the time limits (see "Procedure"). The scoring on PA also followed Wechsler's instructions with a modification: the sequence of the pictures on items 5, 6 and 7 had to follow the absolute correct order to be considered correct. The scoring on the remaining four tasks was as follows: 0-32 on MR, i.e. 0-16 for part A and 0-16 for part B; 0-18 on CGF, i.e. 0-6 on the arc-circle sequence, $0-6$ on the trapezoid sequence and $0-6$ on the star sequence; $0-20$ on the VSM; and 0 to over 40 on each of the five sets on GEF. It should be noted that score distributions were different in the eight measurements.

\section{Data analysis}

A principal component analysis with varimax rotation was first performed on the whole sample (i.e. $n=54$ ) to explore the structure of the test battery. Then a confirmatory factor analysis was applied to build a general model to study how well it accounted for the structure of the spatial abilities shown by either group (Bentler, 1991). A $2 \times 8$ one-way MANOVA with the eight tasks as dependent variables was performed to test differences in space abili- ties between the two groups and a logistic regression analysis (LRA) (SPSS/PC +, 1989) was applied to assess those independent variables of the eight best predicting group membership in the PD patient and NC sample, respectively. The preference for LRA over other techniques like multiple regression analysis (MRA) and linear discriminant analysis (LDA) is suggested by statisticians (Press and Wilson, 1978; Hosmer and Lemeshow, 1989; SPSS/PC, 1989). Also, a $2 \times 8$ one-way MANCOVA was performed on the PD patient subgroup $(n=11)$ with left predominant clinical characteristics (PDL; right hemisphere more affected) and on the PD patient subgroup $(n=10)$ with right predominant clinical characteristics (PDR; left hemisphere more affected) matched on RSPM [mean 6.64 vs. $8.20 ; t(19)=0.47$, N.S.] and age [mean 58.00 years vs. $58.80 ; t(19)=0.29$, N.S.], using disease duration (DD) and disease stage (DS) as covariates. PD patients bilaterally affected were excluded $(n=6)$. Further, to test the prediction that DD may be associated with differences in space ability, PD patients with DD 1-6 years $(n=16 ;$ mean $\mathrm{DD}=3.63$ years; mean $\mathrm{RSPM}=8.31)$ and patients with DD 7-12 years $[n=11$; mean DD $=9.63$ years; mean $\mathrm{RSPM}=6.36 ; t(25)=9.98$, $p<0.001$ and $t(25)=2.88, p<0.01$, respectively] were compared by a $2 \times 8$ MANCOVA, using DS and RSPM together and DS separately as covariates, matched on age [mean 59.81 vs. $57.09 ; t(25)=1.08$, N.S.].

\section{RESULTS}

Table III shows the factor structure extracted from performance on the eight tasks by all subjects, the loadings per task and percentages of explained variance. As can readily be inferred from Table III, the eight tasks form only one factor, the space factor. The tasks, except OA and $\mathrm{CGF}$, are significantly correlated with each other. Interestingly, the tasks BLD, OA and PA, which form the conceptual category of "constructional praxis", and the tasks PC and CGF that relate to visuoperceptual scanning and attention, explained $26.10 \%$ and $61.50 \%$ of the variance,

TABLE III. Factor structure abstracted from performance on eight tasks by the PD patients and NCs $(n=54)$

\begin{tabular}{ccc}
\hline Tasks & $\begin{array}{c}\text { Space factor } \\
\text { loadings }\end{array}$ & $\begin{array}{c}\text { \% variable } \\
\text { explained }\end{array}$ \\
\hline PC & 0.7835 & 56.10 \\
BLD & 0.7661 & 11.10 \\
PA & 0.7218 & 8.20 \\
OA & 0.6237 & 6.80 \\
MR & 0.8094 & 6.30 \\
CGF & 0.6679 & 5.40 \\
VSM & 0.8233 & 2.30 \\
GEF & 0.7715 & 3.80 \\
\hline
\end{tabular}


TABLE IV. Simple intercorrelations matrix of the eight tasks in the two groups of subjects $(n=54)$

\begin{tabular}{|c|c|c|c|c|c|c|c|c|}
\hline & & 2 & 3 & 4 & 5 & 6 & 7 & 8 \\
\hline 1 & PC & $0.67^{\star \star}$ & $0.45^{\star \star}$ & $0.43^{*}$ & $0.57^{\star \star}$ & $0.38^{*}$ & $0.62^{\star \star}$ & $0.51^{\star \star}$ \\
\hline 2 & BLD & - & $0.50^{\star \star}$ & $0.47^{\star \star}$ & $0.57^{\star \star}$ & $0.39^{*}$ & $0.62^{\star \star}$ & $0.51^{* *}$ \\
\hline 3 & PA & & - & $0.47^{\star \star}$ & $0.48^{\star \star}$ & $0.39^{*}$ & $0.49^{\star \star}$ & $0.56^{\star \star}$ \\
\hline 4 & $\mathrm{OA}$ & & & - & $0.36^{*}$ & 0.23 & $0.45^{\star}$ & $0.41^{*}$ \\
\hline 5 & MR & & & & - & $0.64^{\star \star}$ & $0.63^{\star \star}$ & $0.55^{\star \star}$ \\
\hline 6 & CGF & & & & & - & $0.55^{\star \star}$ & $0.43^{\star}$ \\
\hline 7 & VSM & & & & & & - & $0.64^{\star *}$ \\
\hline 8 & GEF & & & & & & & - \\
\hline
\end{tabular}

${ }^{\star} p<0.01$ ( $n=54-2$ d.f.; two-tailed); ${ }^{\star *} p<0.001$ (two-tailed).

respectively. The conceptual categories of orientation and coordination of extrapersonal perspectives, of shifting perceptual set and of visually analysing and reversing mirror image space patterns represented by the MR, GEF and VSM tasks explained $6.3 \%, 3.80 \%$ and $2.30 \%$ of the variance, respectively. Table IV displays simple intercorrelations of the eight tasks as subsidiary evidence of the principal component analysis.

The $2 \times 8$ one-way MANOVA (cf. Table V) showed that space performance was significantly different in PD patients and NCs [approx. $\mathrm{F}(8,45)=13.18, p<0.001$ ] Univariate F-tests $(1,52)$ suggested that except for the group main effect, the PD patients did significantly less well on the seven tasks: $\mathrm{PC}(p<0.001)$; $\mathrm{BLD}(p<0.008)$; $\mathrm{PA}(p<0.001)$; MR $(p<0.001)$; CGF $(p<0.001)$; VSM $(p<0.001)$ and GEF $(p<0.001)$. They did not differ significantly from NCs on the OA task $(p=0.622)$.

The $2 \times 8$ one-way MANCOVA (PD patients with left hemisphere more affected vs. PD patients with right hemisphere more affected; see earlier) yielded no significant main effect [approx. $F(8,10)<1$ ] nor any significant differences in performance on any of the eight tasks [all univariate F ANCOVA tests $(1,17)<1$; on OA $(1.71)$ and VSM (3.24)].

With regard to DD, the $2 \times 8$ one-way MANCOVA showed no significant main effect [approx. $F(8,16)<1$ ] as did all univariate $F$ ANCOVA tests [i.e. $F(1,23)<1$; on MR task (1.57)]. Almost the same data resulted even when DS alone was used as covariate [approx. $F(8,17)=1.02$ on the eight tasks, and all univariate $\mathrm{F}$ ANCOVA tests $(1,24)<2]$. This evidence offers subsidiary support to the assumption that DD and DS may be, to a large extent, overlapping concepts, as intercorrelations of the two variables with one another and with all eight tasks indicate (cf. Table IX). Table V shows means and S.D.s in PD patients and NCs; Table VI in PD patients with left (PDL) and PD patients with right (PDR) side affected; and Table VII in PD patients with early (EDD) and advanced disease duration (ADD), respectively. Figures 1, 2 and 3 also show performance on the same tasks in the three group pairs.

\section{Logistic regression analysis}

To estimate the probability of an event occurring, i.e. of a subject being or not being classified as a PD patient, the LRA was applied. Because performance on the OA task did not differ in the two groups, seven of the eight psychological measures were used as independent variables. Group membership, that is, being a control subject versus being a PD patient, was used as dependent variable. According to results yielded by the LRA, 25 individuals were correctly classified as control subjects $(92.59 \%)$ and 22 individuals as PD patients $(81.48 \%)$. Five subjects were misclassified as controls $(19.52 \%)$ and two as PD patients $(7.41 \%)$. The overall correct classification rate was $87.04 \%$.

Of the seven independent variables only two, the MR [coefficient $=-0.7575$; Wald test $=6.6063, p<0.01$; $R$ (change) $=-0.2481$ ] and the VSM [coefficient $=$ -0.6204 ; Wald test $=6.8600, p<0.008 ; R$ (change) $=$ -0.2548 ], predict group membership for the 54 subjects tested. It should be mentioned that a positive value for $R$ statistic indicates that as the $R$ variable increases in value $(0$ to +1$)$ so does the likelihood of the event occurring. The opposite is also true: that is, if $R$ is negative (as is the case for these data) and its value decreases $(0$ to -1$)$ the likelihood of the event not occurring also decreases (i.e. for a subject not being a PD patient and/or not being a control, respectively) ${ }^{1}$. Two further statistics, the $-2 \log$

' That is, not being a PD patient entails being a control subject, and not being a control subject entails being a PD patient.

TABLE V. Means and S.D.s for the eight tasks and MANOVA and univariate F-tests in PD patients and NC subjects

\begin{tabular}{|c|c|c|c|c|c|c|c|c|c|c|c|c|c|c|c|c|c|}
\hline & \multicolumn{2}{|l|}{$\mathrm{PC}$} & \multicolumn{2}{|l|}{ BLD } & \multicolumn{2}{|l|}{ PA } & \multicolumn{2}{|l|}{$\mathrm{OA}$} & \multicolumn{2}{|l|}{ MR } & \multicolumn{2}{|l|}{ CGF } & \multicolumn{2}{|c|}{ VSM } & \multicolumn{2}{|c|}{ GEF } & \multirow{2}{*}{$\begin{array}{c}\text { MANOVA } \\
\mathrm{F}(8,45) \\
p\end{array}$} \\
\hline & Mean & S.D. & Mean & S.D. & Mean & S.D. & Mean & S.D. & Mean & S.D. & Mean & S.D. & Mean & S.D. & Mean & S.D. & \\
\hline PD patients $(n=27)$ & 7.37 & 3.06 & 20.88 & 3.75 & 2.11 & 1.26 & 14.77 & 7.81 & 26.37 & 2.65 & 14.04 & 3.20 & 10.93 & 2.61 & 28.33 & 11.50 & \\
\hline NC subjects $(n=27)$ & 10.63 & 2.03 & 26.22 & 4.64 & 3.33 & 0.51 & 15.71 & 5.54 & 31.62 & 1.13 & 17.52 & 3.66 & 15.59 & 1.93 & 38.77 & 8.10 & \\
\hline \multicolumn{18}{|c|}{$\begin{array}{l}\text { Univariate } \\
\text { Un }\end{array}$} \\
\hline F-tests $(1,52)$ & 20. & .56 & & 68 & 19 & .18 & & 246 & 34. & .58 & 23. & .07 & 40. & 51 & 26. & .73 & 13.18 \\
\hline$p$ & $<0$. & .001 & $<0$ & .001 & $<0$. & .008 & & .S. & $<0$ & .001 & $<0$. & .001 & $<0$. & 001 & $<0$. & .001 & $<0.001$ \\
\hline
\end{tabular}


TABLE VI. Means for the eight tasks in PD with left (PDL) versus right (PDR) clinically lateralized effect matched on age and RSPM, and with disease duration (DD) and stage (DS) as covariates

\begin{tabular}{lccccccrc}
\hline & PC & BLD & PA & OA & MR & CGF & VSM & GEF \\
\hline PDL $(n=11)$ & 7.72 & 20.72 & 2.09 & 12.18 & 26.81 & 13.18 & 9.45 & 26.72 \\
PDR $(n=10)$ & 7.30 & 21.40 & 2.40 & 17.60 & 26.80 & 14.40 & 12.00 & 28.30 \\
\hline
\end{tabular}

TABLE VII. Means for the eight tasks in PD with early disease duration (1-6 years; EDD) and advanced disease duration (7-12 years; ADD) matched on age and with disease stage (DS) and RSPM as covariates

\begin{tabular}{lcccccccc}
\hline & PC & BLD & PA & OA & MR & CGF & VSM & GEF \\
\hline $\operatorname{EDD~}(n=16)$ & 8.13 & 22.50 & 2.44 & 16.38 & 26.00 & 14.81 & 11.19 & 28.06 \\
$\operatorname{ADD~}(n=11)$ & 6.27 & 19.41 & 1.64 & 12.46 & 26.64 & 12.64 & 10.00 & 26.64 \\
\hline
\end{tabular}

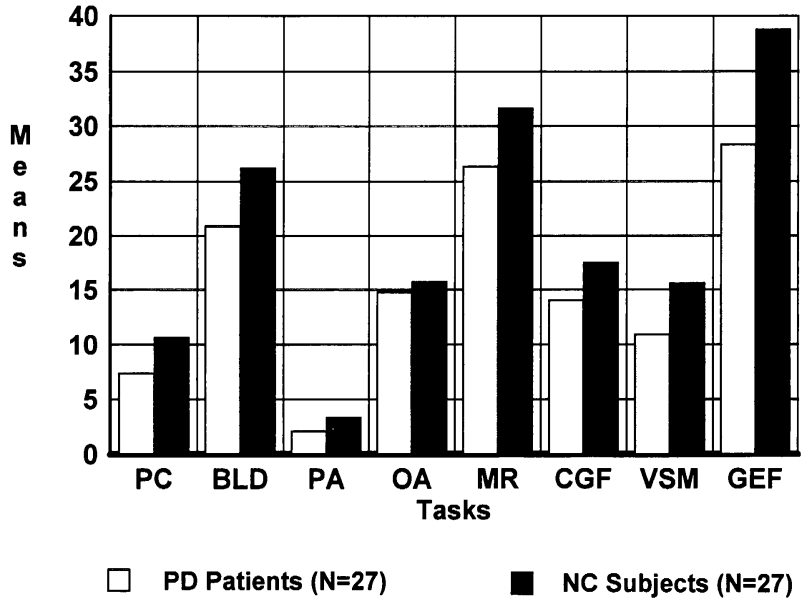

FIG. 1. Performance by PD patients and NCs on the eight tasks.

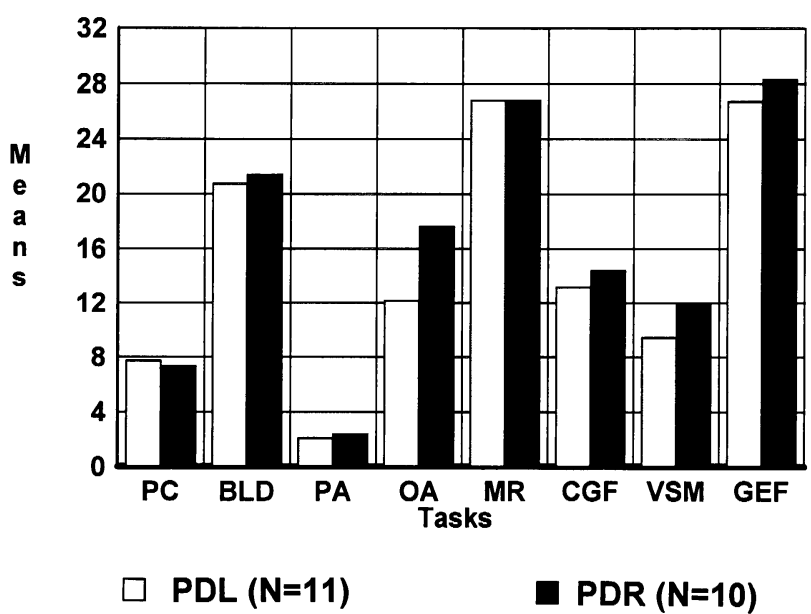

FIG. 2. Differences in performance by PDL and PDR subgroups on the eight tasks.

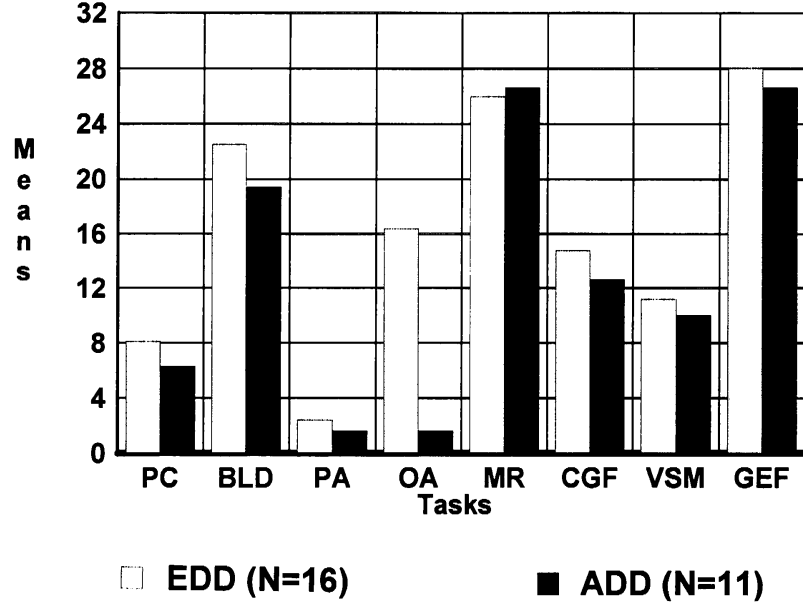

FIG. 3. Differences in performance by EDD and ADD subgroups on the eight tasks.

$\left[\chi^{2}(51)=28.656, p=0.9952\right]$ and goodness of fit $\left[\chi^{2}(51)=29.439, p=0.9933\right]$, with all of the independent variables indicate that the present model does not differ significantly from the perfect model, i.e. from choosing those parameter estimates which could make the observed results as likely as possible. The LRA was not used in the other groups because the restrictions required by this analysis could not be met.

\section{Confirmatory factor analysis}

The use of this analysis aimed to build a general model to account for structural differences in space abilities between PD patients and NCs. Thus, the analysis yielded one space factor for either group, supporting the principal component analysis as Table VIII depicts.

According to Table VIII, seven of the eight variable loadings are significant on the space factor in PD patients, 
TABLE VIII. Results summary from the confirmatory factor analysis applied on the eight variables in the PD patients and NC subjects

\begin{tabular}{|c|c|c|c|c|c|c|}
\hline & \multicolumn{4}{|c|}{ Space factor variable loadings } & \multirow[t]{2}{*}{$\chi^{2}(40$ d.f. $)$} & \multirow[t]{2}{*}{ Comparative fit index } \\
\hline & & PD patients & & NC subjects & & \\
\hline PC & 0.718 & $(4.079)^{\star}$ & 0.179 & $(0.818)$ & 0.400 (N.S.) & 0.983 \\
\hline BLD & 0.812 & $(4.864)^{\star}$ & 0.095 & $(0.434)$ & & \\
\hline PA & 0.557 & $(2.954)^{\star}$ & 0.751 & $(3.857)^{\star}$ & & \\
\hline$O A$ & 0.885 & $(5.559)^{\star}$ & 0.444 & $(2.125)^{\star}$ & & \\
\hline MR & 0.585 & $(3.133)^{\star}$ & 0.437 & $(2.084)^{\star}$ & & \\
\hline CGF & 0.330 & (1.648) & 0.324 & (1.511) & & \\
\hline VSM & 0.664 & $(3.988)^{\star}$ & 0.780 & $(4.025)^{\star}$ & & \\
\hline GEF & 0.706 & $(3.680)^{*}$ & 0.506 & $(2.455)^{\star}$ & & \\
\hline
\end{tabular}

${ }^{*} Z$ values are significant compared with 1.96 standard value.

whereas five of the eight variable loadings are significant on the same factor in NCs. As to the general model, the $\chi^{2}(40)=41.612, p=0.4004$ and the comparative fit index $(\mathrm{CFI})=0.983$ (very close to value 1.00 ), show that this general model accounts for the data in a satisfactory way for either group (Bentler, 1991), indicating that the population from which the two groups come is homogeneous.

\section{Correlations of psychological measures and clinical} characteristics in PD patients

According to Table IX, Pearson product moment correlation coefficients show that the PC, BLD, OA, MR, CGF and VSM tasks are significantly correlated with each other in PD patients. The picture is very similar to the one presented in Table IV for PD patients and NC subjects. Interestingly, the DD and DS are negatively correlated with all eight tasks. Of these correlations only $37.50 \%$ are significant. Also, more than one-third $(37.50 \%)$ of the correlations of tremor, bradykinesia and rigidity and the eight tasks were low negative; the remaining $(62.50 \%)$ were low positive. The MMSE was significantly correlated with four of the eight tasks and low negatively correlated with three of the five clinical characteristics (i.e. DD, DS and $\mathrm{BR})$.

\section{DISCUSSION}

Performance by PD patients on the five conceptual categories of space ability is significantly lower compared to that by NCs according to data analysis (cf. Table V and Fig. 1). In particular, the findings confirm prediction (1), indicating that PD patients are impaired in tasks which require ability to construct whole entities (BLD, OA) and/or conceptual sequences (PA) by matching separate elements. This evidence accords, except for the OA task which did not reach significance, with other results on the same tasks (Pirozzolo et al., 1982; Globus et al., 1985; Goldenberg et al., 1986; Brown and Marsden, 1986, 1988; Gotham et al.,

TABLE IX. Simple intercorrelations matrix of the eight psychological measurements and the clinical characteristics in PD patients $(n=27)$

\begin{tabular}{|c|c|c|c|c|c|c|c|c|c|c|c|c|c|c|}
\hline & & 2 & 3 & 4 & 5 & 6 & 7 & 8 & 9 & 10 & 11 & 12 & 13 & 14 \\
\hline 1 & PC & $0.66^{\star \star \star}$ & $0.33^{\star}$ & $0.61^{* \star \star}$ & $0.40^{\star}$ & 0.10 & $0.55^{\star \star}$ & $0.48^{\star \star}$ & -0.23 & -0.17 & -0.18 & 0.6 & 0.12 & 0.27 \\
\hline 2 & BLD & - & $0.49^{\star *}$ & $0.69^{\star \star \star}$ & $0.56^{\star \star}$ & 0.27 & $0.40^{*}$ & $0.61^{\star \star *}$ & $-0.34^{\star}$ & $-0.46^{*}$ & 0.27 & -0.08 & -0.07 & $0.32^{\star}$ \\
\hline 3 & PA & & - & $0.61^{\star \star \star}$ & 0.24 & 0.14 & 0.25 & 0.24 & $-0.38^{\star}$ & $-0.41^{*}$ & 0.05 & 0.01 & -0.10 & 0.04 \\
\hline 4 & $O A$ & & & - & $0.47^{\star \star}$ & 0.28 & $0.63^{\star \star \star}$ & $0.63^{\star \star \star}$ & $-0.38^{\star}$ & -0.13 & 0.08 & 0.12 & 0.26 & $0.35^{\star}$ \\
\hline 5 & MR & & & & - & $0.47^{\star}$ & $0.38^{*}$ & $0.40^{\star}$ & -0.06 & -0.05 & 0.22 & 0.05 & 0.24 & $0.51^{\star *}$ \\
\hline 6 & CGF & & & & & - & 0.30 & 0.18 & $-0.50^{\star *}$ & -0.08 & 0.13 & -0.01 & 0.19 & 0.16 \\
\hline 7 & VSM & & & & & & - & $0.55^{\star \star}$ & -0.20 & -0.06 & -0.08 & -0.10 & 0.12 & $0.37^{\star}$ \\
\hline 8 & GEF & & & & & & & - & -0.12 & -0.21 & 0.20 & -0.17 & -0.16 & 0.17 \\
\hline 9 & DD & & & & & & & & - & $0.47^{\star *}$ & -0.21 & -0.18 & 0.02 & 0.00 \\
\hline 10 & DS & & & & & & & & & - & -0.17 & $-0.56^{\star *}$ & $0.54^{\star \star}$ & -0.07 \\
\hline 11 & TR & & & & & & & & & & - & -0.20 & -0.11 & 0.00 \\
\hline 12 & BR & & & & & & & & & & & - & $0.56^{\star \star}$ & -0.03 \\
\hline 13 & $R G$ & & & & & & & & & & & & - & 0.30 \\
\hline 14 & MMSE & & & & & & & & & & & & & 一 \\
\hline
\end{tabular}

DD, disease duration; DS, disease stage; TR, tremor; BR, bradykinesia; RG, rigidity; MMSE, Mini-Mental State Examination. ${ }^{\star} p<0.05, n=27-2$ d.f., one-tailed for all levels of significance; ${ }^{\star *} p<0.01 ;{ }^{* \star *} p<0.001$. 
1988; Hietanen and Teräväinen, 1988; Morris et al., 1988; Ogden et al., 1990; Levin et al., 1991; Testa et al., 1993). Differences between PD patients and NCs in tasks such as the ones tested which require self-generated strategies for planning and organizing cognitive behaviour in general, have been attributed to frontal (Lees and Smith, 1983; Cools et al., 1984; Brown and Marsden, 1988; Gotham et al., 1988) and prefrontal lobe dysfunction (Taylor et al., 1986). However, differing performance in PD patients between BLD and PA on one hand, and OA on the other, suggest that frontal lobe function may not be a homogeneous entity even for tasks thought to tap very similar cognitive behaviour, as Gotham et al. (1988) have also argued. Further, the fact that the OA task was significantly correlated with the BLD $(0.69)$ and PA $(0.61)$ tasks (Table IX) indicates that subtle cognitive functions of frontal lobe are not reflected on all tasks, despite having strong psychometric affinities with each other.

Visuoperceptual attention was also impaired in PD patients compared with NCs on the PC and CGF tasks (cf. Table $\mathrm{V}$ and Fig. 1), providing support for prediction (2). The PC task does not require motor proficiency, whereas the CGF task demands very simple manipulation of stimuli. Both tasks call for a sustained visuoperceptual attention and a moderately fast $(20 \mathrm{~s})$ scanning process for filling in missing patterns (PC) and matching differences between stimuli (CGF). Similar results were also found in other studies, using similar visuoperceptual tasks which, mutatis mutandis, tap the same and/or similar processes (Boller et al., 1984; Stern et al., 1984). Observed dysfunction of attention in PD has been explained in terms of distractibility (Sharpe 1990a, 1992), of visual neglect (Villardita et al., 1983), of difficulty in self-directed behavioural planning (Taylor et al., 1986), or reduced resources in the supervisory attentional system (Brown and Marsden, 1988) and of difficulties experienced by PD patients in generating and/or executing motor plans (Stern et al., 1984). Brown and Marsden's (1988) approach, adapted mainly from Baddeley (1986) and Shallice (1982), is more appealing and seems to account for data stemming from even simpler experimental conditions than ours. According to Brown and Marsden, deficit in attentional resources in PD patients depends both on the extent the supervisory attentional system controls the internally generated information (i.e. cognitive set) and on the degree the system can access this information in order to control the attentional resources. Indeed, the PD patients were less efficient in searching for missing patterns in the $\mathrm{PC}$ condition and in generating progressive sequences by taking into account the preceding and following visuospatial patterns in the CGF task.

In contrast to prediction (3a), ability of left-right, backfront orientation and mental rotation in taking extrapersonal (allocentric) space perspectives with two- and three-dimensional relationships on the MR task (parts A and $\mathrm{B}$, respectively) was significantly different in $\mathrm{PD}$ patients and NCs (cf. Table V and Fig. 1). This evidence does not agree with data reported by Brown and Marsden (1986) and Taylor et al. (1986) on left-right orientation and on mental rotation. Instead, these results are in keeping with findings from previous research (Pirozzolo et al., 1982; Goldenberg et al., 1986; Hovestadt et al., 1987; Levin et al., 1991; Testa et al., 1993). It seems that misorientation and/or failure by PD patients to assist extrapersonal perspectives in left-right and back-front Euclidean space (two-dimensional) and three-dimensional relationships in mental rotation is an indication of inflexibility in alternating cognitive set, by decentring successively from one perspective to another. Further, differences in the MR untimed task (parts A and B) provide convincing evidence that difficulty in alternating mental sets in PD patients is independent of time and may be assigned to the instability they experience, as Flowers and Robertson (1985) claim.

Dysfunction in attentional shifts and/or changing cognitive set was clear on the GEF task for PD patients (cf. Table V and Fig. 1) in agreement with prediction (3b) and with findings reported by Levin et al. (1989) and Mohr $e t$ al. (1987). Observations during testing revealed that the patients, after they counted the simple and most obvious figures, very often stopped before time expired, saying they "could not see any more figures". This evidence suggests that PD patients are compromised in analysing and, thereby, alternating successively between figure-ground relationships in the GEF test. Or, alternatively, they may be dominated by a Gestalt principle and, therefore, reject and/or ignore figures which do not comply with this principle. Levin et al. (1991) found that embedded figures distinguish not only between PD patients and NCs but also between PD subgroups differing in stages of dementia. The fact that GEF performance was negatively non-significantly correlated with bradykinesia $(-0.17)$ and rigidity $(-0.16)$ and positively non-significantly with tremor (0.20), clinical characteristics associated with the basal ganglia dysfunction (cf. recent review by Phillips et al., 1993), indicates that involvement of posterior parietal cortex in alternating figure-ground relationships may not be affected by motor cortical areas to the extent anticipated [cf. prediction (3b)]. Or, impairment of alternating rival spatial patterns on embedded figures and dysfunction of basal ganglia may emerge independently as a result of the $\mathrm{PD}$, and irrespective of clinical characteristics, motor and time requirements as studies show on spatial cognition (Pirozzolo et al., 1982; Hovestadt et al., 1987; Levin et al., 1991), on formation of concept categories (Lees and Smith, 1983; Taylor et al., 1986; Brown and Marsden, 1988; Gotham et al., 1988) and on extraction of logical rules (Flowers and Robertson, 1985). 
Immediate visuospatial recognition memory of mirror image space patterns was significantly different in PD patients and NCs, in contrast to prediction (4) (cf. Table V and Fig. 1). This ability was associated with the VSM task. The subjects, after $10 \mathrm{~s}$ visualization of a four element mirror image pattern, had to match with its counterpart out of four displayed space patterns within $10 \mathrm{~s}$ immediately after the presentation. PD patients showed greater difficulty in immediate visuospatial memory (recognition) in line with other data (Pirozzolo et al., 1982; Boller et al., 1984; Globus et al., 1985; Sahakian et al., 1988; Levin et al., 1989; Owen et al., 1993 for medicated patients with severe clinical symptoms). The fact that the left lateralized subgroup of PD patients did not differ significantly from the right lateralized subgroup [mean 9.45 versus 12.00 , respectively; cf. Table VI and prediction (5a)] on the same task suggests that the PD patients were a homogeneous group. Subsequently, immediate visuospatial memory differences from NCs did not result from skewed values of a specific subgroup, because intelligence, age, disease duration and disease stage were controlled. Instead, differences in visuospatial memory show that PD patients are defective in recognition of mirror image patterns. The most likely explanations are the complexity of the task and the limitation it imposed on the information the patients could process during the time allowed $(10 \mathrm{~s})$; or difficulty the patients experienced in developing effective strategies of encoding information during the task presentation; or even that the patients did not use all the time allowed to process the stimulus in hand despite being prompted. These findings, however, cannot offer a clear answer to whether the observed differences can be attributed to dysfunction lying with the encoding process or/and with the retention or retrieval (cf. Pigott and Milner, 1993), because the test was an immediate recognition task. This issue has been designed for further exploration in another study. On the other hand, the differences found in Pigott and Milner's (1993) study between delayed and immediate visuospatial memory in individuals with unilateral left, right temporal and frontal lobe excisions suggest that different mechanisms may underlie the two processes, and involvement of subcortical-cortical neurotransmitter systems inducing these processes may also vary in PD patients. Further, inspection of Table IX reveals moderate to strong correlations ( 0.38 to 0.63 ) of the VSM task with five of the seven tasks, whereas correlations with all clinical variables were non-significantly negative, except with rigidity $(R G)$ which was non-significantly positive.

Left (PDL) versus right (PDR) clinically lateralized effect and disease duration effect

With regard to prediction (5a), the PDL subgroup (right hemisphere more affected) was inferior on six tasks out of eight (cf. Table VI and Fig. 2) compared with the PDR subgroup (left hemisphere affected). But neither overall performance nor univariate tests showed significant differences between PDL and PDR subgroups in general agreement with results reported by Taylor et al. (1986) on visuospatial functions. In contrast, the present data do not confirm findings by Mehta and Newcombe (1991) and Mehta et al. (1987), which show that spatial ability of left hemisphere is significantly different from one type of task to another and from the right hemisphere on various tasks. Data on DD do not support prediction (5b), although there was a clear trend for the ADD subgroup to perform less well than the EDD subgroup on seven out of eight tasks (cf. Table VII and Fig. 3).

Taken together, the findings on PDL and PDR and EDD and ADD paired subgroups with age, intelligence, DS and DD covariates controlled (cf. "Data analysis"), suggest that first, PD patients as a group are homogeneous and, second, differences found between them and NCs are independent of psychometric intelligence, as other investigators claim (Lees and Smith, 1983; Boller et al., 1984; Brown et al., 1984; Brown and Marsden, 1986; Taylor et al., 1986; Caltagirone et al., 1989; Sharpe, 1990a), of age (Brown and Marsden, 1986), of DD (Brown et al., 1984) and of DS (present data; but cf. Boller et al., 1984; Owen et al., 1993).

\section{Group membership in PD patients and NCs}

Having established a homogeneous group of subjects within the PD patients, and a group of controls carefully matched on a number of variables (cf. "Subjects" section), the LRA results indicate that $81.48 \%$ of the patients show a clear impairment of spatial cognition on a subset of measures, i.e. orientation and MR and VSM. These two measures classified as many control subjects as $92.59 \%$. It should be stressed that these two measures have been designed for experimental purpose in contrast to PC, BLD, PA and OA standardized subtests (Wechsler, 1955), which despite large significant differences (except OA, cf. Table V) failed to provide classification efficacy. In the face of this evidence, it is reasonable to suggest that distribution of PD patients falls along a continuum of spatial cognition, ranging from intact intellectual ability (19.52\%) to cognitive impairment $(81.48 \%)$. The opposite holds true on the control group, i.e. cognitive impairment covers $7.41 \%$ of the spatial ability continuum and $92.59 \%$ are unimpaired.

What significance should be attributed to differences in performance by PD patients with regard to these measures? Are these differences quantitative or qualitative in nature?

With regard to the first question the LRA suggests that of the five categories of spatial cognition tested only two, the MR and VSM measures, are sensitive to classify the PD patients and NCs into two distinct groups. What is 
implicated is not that these two measures can replace the existing neuropsychological ones used for classifying PD; instead, tasks like the two mentioned may assist diagnosis. The fact that the first task was untimed and the second timed suggests that time and movement coordination, respectively, may not be critical factors in assessing certain aspects of cognitive functions in PD as other data also show (Taylor et al., 1986; Ogden et al., 1990).

Concerning the second question, whether the differences are quantitative or qualitative in nature between PD patients and NCs, the confirmatory factor analysis supports the former. That is, there is one space factor for either group and the data are accounted for by a general model whose goodness of fit $\left(\chi^{2}\right.$ value and CFI) complies well with the statistical restrictions. Further, differences in performances as the observed do not necessarily imply that PD patients apply different patterns of cognitive behaviour stemming also from different cognitive mechanisms. Instead, PD patients differ in number but not in the form of answer patterns compared with NCs, a demonstration that both groups result from a homogeneous population.

\section{Correlation of performance with clinical characteristics}

Significant negative correlations of BLD, PA, OA and CGF tasks with DD suggest that disease affects spatial cognition implicating the ability to construct whole entities (BLD, OA) and/or conceptual (PA) and visuoperceptual sequences (CGF) (cf. Table IX). This is true on DS with BLD and PA tasks only but not with OA and CGF, whereas the GEF task which requires finer motor coordination and VSM which does not need motor efficacy but mere pointing are not significantly (negatively or positively) correlated with DD and DS.

Further, four of the seven timed tasks were significantly negatively correlated with DD (BLD, PA, OA, CGF) and two of them (BLD, PA) with DS. This latter evidence indicates that relationships between time as a performance parameter and motor requirements selectively affect cognition within the same clinical characteristic (i.e. DD and/or DS). This is particularly true of all seven timed tasks bearing no significant (negative or positive) correlation with TR, BR and RG clinical characteristics (cf. Table IX), an indication that relationships between clinical characteristics and spatial cognition are at variance (cf. also Taylor et al., 1986; Cooper and Sagar, 1993).

In conclusion, the most sensitive criteria which discriminate PD patients and NC subjects reliably are leftright, back-front Euclidean orientation, three-dimensional mental rotation and immediate visuospatial recognition memory of mirror image patterns. These differences are claimed to be of a quantitative rather than of a qualitative nature.

\section{REFERENCES}

Adelstein TB, Kesner RP and Strassberg DS (1992) Spatial recognition and spatial order memory in patients with dementia of the Alzheimer's type. Neuropsychologia, 30, 59-67.

American Psychiatric Association (1980) Diagnostic and Statistical Manual of Mental Disorders, 3rd edn. APA, Washington, DC.

Andersen RA (1988) The neurobiological basis of spatial cognition: Role of the parietal lobe. In: Spatial Cognition: Brain Bases and Development (Eds J Stiles-Davis, M Kritchevsky and U Bellugi), pp. 58-80. Lawrence Erlbaum Associates, NJ.

Baddeley A (1986) Working Memory. Oxford University Press, Oxford.

Bentler PM (1991) EQS: Structural Equations Program Manual. BMDP Statistical Software, Los Angeles, CA.

Boller F, Passafiume D, Keefe NC, Rogers K, Morrow L and Kim Y (1984) Visuospatial impairment in Parkinson's disease. Archives of Neurology, 41, 485-490.

Bradley VA, Welch JL and Dick DJ (1989) Visuospatial working memory in Parkinson's disease. Journal of Neurology, Neurosurgery, and Psychiatry, 52, 1228-1235.

Breen EK (1993) Recall and recognition memory in Parkinson's disease. Cortex, 29, 91-102.

Brown RG and Marsden CD (1986) Visuospatial function in Parkinson's disease. Brain, 109, 987-1002.

Brown RG and Marsden CD (1988) Internal versus external cues and the control of attention in Parkinson's disease. Brain, 111, 323-345.

Brown RG, Marsden CD, Quinn N and Wyke MA (1984) Alterations in cognitive performance and affect-arousal state during fluctuations in motor function in Parkinson's disease. Journal of Neurology, Neurosurgery, and Psychiatry, 47, 454-465.

Caltagirone C, Carlesimo A, Nocentini U and Vicari S (1989) Defective concept formation in Parkinsonians is independent from mental deterioration. Journal of Neurology, Neurosurgery, and Psychiatry, 52, 334-337.

Channon S, Jones M-C and Stephenson S (1993) Cognitive strategies and hypothesis testing during discrimination learning on Parkinson's disease. Neuropsychologia, 31, 75-82.

Cools AR, Van Den Bercken JHL, Horstink MWI, Van Spaendonck KPM and Berger HJC (1984) Cognitive and motor shifting aptitude disorder in Parkinson's disease. Journal of Neurology, Neurosurgery, and Psychiatry, 47, 443-453.

Cooper JA and Sagar HJ (1993) Encoding deficits in untreated Parkinson's disease. Cortex, 29, 251-265.

De Renzi E (1982) Disorders of Space Exploration and Cognition. Wiley, Chichester.

Della Sala S, Di Lorenzo G, Giordano A and Spinnler H (1986) Is there a specific visuo-spatial impairment in Parkinsonians? Journal of Neurology, Neurosurgery, and Psychiatry, 49, 1258-1265.

Fahn S, Elton RL and Members UPDRS Development Committee (1987) Unified Parkinson's disease rating scale. In: Recent Developments in Parkinson's Disease II (Eds S Fahn, CD Marsden, M Goldstein and DB Calne), pp. 153-163. Macmillan Healthcare Information, Florham Park, NJ.

Feuerstein R (1980) Instrumental Enrichment: An Intervention Program for Cognitive Modifiability. University Park Press, Baltimore.

Flowers KA and Robertson C (1985) The effect of Parkinson's disease on the ability to maintain a mental set. Journal of Neurology, Neurosurgery, and Psychiatry, 48, 517-529. 
Flowers KA, Pearce I and Pearch JMS (1984) Recognition memory in Parkinson's disease. Journal of Neurology, Neurosurgery, and Psychiatry, 47, 1174-1181.

Folstein MF (1983) The Mini-Mental State Examination. In: Assessment in Geriatric Psychopharmacology (Eds T Crook, S Ferris and R Bartus), pp. 47-51. Mark Poweley Ass., N. Canaan, CT.

Folstein MF, Folstein SE and McHugh PR (1975) "Mini-Mental State": A practical method for grading the cognitive state of patients for the clinician. Journal of Psychiatric Research, 12, 189-198.

Globus M, Mildworf B and Melamed E (1985) Cerebral blood flow and cognitive impairment in Parkinson's disease. Neurology, 35, 1135-1139.

Goldenberg G, Wimmer A, Auff E and Schnabert G (1986) Impairment of motor planning in patients with Parkinson's disease: Evidence from ideomotor apraxia testing. Journal of Neurology, Neurosurgery, and Psychiatry, 49, 1266-1272.

Gotham AM, Brown RG and Marsden CD (1988) 'Frontal' cognitive function in patients with Parkinson's disease 'on' and 'off' levodopa. Brain, 111, 299-321.

Grossman M, Carvell S, Gollomp S, Stern MB, Vernon RN and Hurtig HI (1991) Sentence comprehension and praxis deficits in Parkinson's disease. Neurology, 41, 1620-1626.

Grossman M, Carvell S, Stern MB, Gollomp S and Hurtig HI (1992) Sentence comprehension in Parkinson's disease: The role of attention and memory. Brain and Language, 42, 347-384.

Grossman M, Carvell S and Peltzer L (1993) The sum and substance of it: The appreciation of mass and count quantifiers in Parkinson's disease. Brain and Language, 44, 351-384.

Hietanen M and Teräväinen H (1988) The effect of age of disease onset on neuropsychological performance in Parkinson's disease. Journal of Neurology, Neurosurgery, and Psychiatry, 51, 244-249.

Hoehn MM and Yahr MD (1967) Parkinsonism: Onset progression and mortality. Neurology, 17, 427-442.

Hosmer D and Lemeshow S (1989) Applied Logistic Regression. John Wiley and Sons, New York.

Hovestadt A, de Jong GJ and Meerwaldt JD (1987) Spatial disorientation as an early symptom of Parkinson's disease. Neurology, 37, 485-487.

Huber SJ, Shuttleworth EC, Paulson GW, Bellchambers MJG and Clapp LE (1986) Cortical vs subcortical dementia. Archives of Neurology, 43, 392-394.

Illes J (1989) Neurolinguistic features of spontaneous language production dissociate three forms of neurodegenerative disease: Alzheimer's, Huntington's and Parkinson's. Brain and Language, 37, 628-642.

Illes J, Metter EJ, Hanson WR and Iritani S (1988) Language production in Parkinson's disease. Acoustic and linguistic considerations. Brain and Language, 33, 146-160.

Kosslyn SM (1987) Seeing and imagining in the cerebral hemispheres: A computational approach. Psychological Review, 94, 148-175.

Kritchevsky M (1988) The elementary spatial functions of the brain. In: Spatial Cognition: Brain Bases and Development (Eds J Stiles-Davis, M Kritchevsky and U Bellugi), pp. 111140. Lawrence Erlbaum Associates, NJ.

Lees AJ and Smith E (1983) Cognitive deficits in the early stages of Parkinson's disease. Brain, 106, 257-270.

Levin BE (1990) Spatial cognition in Parkinson disease. Alzheimer Disease and Associated Disorders, 4, 161-170.

Levin BE, Llabre MM and Weiner WJ (1989) Cognitive impair- ments associated with early Parkinson's disease. Neurology, 39, 557-561.

Levin BE, Llabre MM, Reisman S, Weiner WJ, Sanchez-Ramos J, Singer C and Brown MC (1991) Visuospatial impairment in Parkinson's disease. Neurology, 41, 365-369.

Lieberman P (1991) Uniquely Human: The Evolution of Speech, Thought and Self-less Behavior. Harvard University Press, Cambridge, MA.

Lieberman P, Friedman J and Feldman LS (1990) Syntax comprehension deficits in Parkinson's disease. Journal of Nervous and Mental Disease, 178, 360-365.

Lieberman P, Kako E, Friedman J, Tajchman G, Feldman LS and Jiminez EB (1992) Speech production, syntax comprehension, and cognitive deficits in Parkinson's disease. Brain and Language, 43, 169-189.

Mehta Z and Newcombe F (1991) A role for the left hemisphere in spatial processing. Cortex, 27, 153-167.

Mehta Z, Newcombe F and Damasio H (1987) A left hemisphere contribution to visuospatial processing. Cortex, 23 , 447-461.

Mohr E, Fabrini G, Ruggieri S, Fedio P and Chase TN (1987) Cognitive concomitants of dopamine system stimulation in Parkinsonian patients. Journal of Neurology, Neurosurgery, and Psychiatry, 50, 1192-1196.

Morris RG, Downes JJ, Sahakian BJ, Evenden JL, Heald A and Robbins TW (1988) Planning and spatial working memory in Parkinson's disease. Journal of Neurology, Neurosurgery, and Psychiatry, 51, 757-766.

Morrow L and Ratcliff G (1988) Neuropsychology of spatial cognition: Evidence from cerebral lesions. In: Spatial Cognition: Brain Bases and Development (eds J Stiles-Davis, M Kritchevsky and U Bellugi), pp. 5-32. Lawrence Erlbaum Associates, NJ.

Mortimer JA, Pirozzolo FJ, Hansch EC and Webster DD (1982) Relationship of motor symptoms to intellectual deficits in Parkinson disease. Neurology, 32, 133-137.

Natsopoulos D, Katsarou Z, Bostantzopoulou S, Grouios G, Mentenopoulos G and Logothetis J (1991a) Strategies in comprehension of relative clauses by Parkinsonian patients. Cortex, 27, 255-268.

Natsopoulos D, Mentenopoulos G, Bostantzopoulou S, Grouios G, Katsarou Z and Logothetis J (1991b) Understanding of relational time terms "before" and "after" in Parkinsonian patients. Brain and Language, 40, 444-458.

Natsopoulos D, Grouios G, Bostantzopoulou S, Mentenopoulos G, Katsarou Z and Logothetis J (1993) Algorithmic and heuristic strategies in comprehension of complement clauses by patients with Parkinson's disease. Neuropsychologia, 31, 951-964.

Ogden JA, Crowdon JH and Corkin S (1990) Deficits on visuospatial tests involving forward planning in high-functioning Parkinsonians. Neuropsychiatry, Neuropsychology, and Behavioral Neurology, 3, 125-139.

Owen AM, Beksinska M, James M, Leigh PN, Summers BA, Marsden CD, Quinn NP, Sahakian BJ and Robbins TW (1993) Visuospatial memory deficits at different stages of Parkinson's disease. Neuropsychologia, 31, 627-644.

Phillips JG, Bradshaw JL, Iansek R and Chiu E (1993) Motor functions of the basal ganglia. Psychological Research, 55, 175-181.

Pigott S and Milner B (1993) Memory for different aspects of complex visual scenes after unilateral temporal-or frontallobe resection. Neuropsychologia, 31, 1-15.

Pirozzolo FJ, Hansch EC, Mortimer JA, Webster DD and 
Kuskowski MA (1992) Dementia in Parkinson Disease: A neuropsychological analysis. Brain and Cognition, 1, 71-83.

Press J and Wilson S (1978) Choosing between logistic regression and discriminant analysis. Journal of the American Statistical Association, 73, 699-705.

Rafal RD, Posner MI, Walker JA and Friedrich FJ (1984) Cognition and the basal ganglia: Separating mental and motor components of performance in Parkinson's disease. Brain, 107, 1083-1094.

Ratcliff G (1982) Disturbances of spatial orientation associated with cerebral lesions. In: Spatial Abilities: Development and Psychological Foundations (Ed. M. Potegal), pp. 301-331. Academic Press, New York.

Raven JC (1958) Standard Progressive Matrices: Sets A, B, C, D and E. H.K. Lewis and Co. Ltd, London.

Sagar HJ (1991) Specificity of cognitive impairment in neurological disease: A methodological critique of Parkinson's disease. Behavioural Neurology, 4, 89-102.

Sagar HJ, Cohen NJ, Sullivan EV, Corkin S and Crowdon JH (1988a) Remote memory function in Alzheimer's disease and Parkinson's disease. Brain, 111, 185-206.

Sagar HJ, Sullivan EV, Gabrieli JDE, Corkin S and Growdon JH (1988b) Temporal ordering and short-term memory deficits in Parkinson's disease. Brain, 111, 525-539.

Sahakian BJ, Morris RG, Evenden JL, Heald A, Levy R, Philpot $M$ and Robbins TW (1988) A comparative study of visuospatial memory and learning in Alzheimer-type dementia, and Parkinson's disease. Brain, 111, 695-718.

Shallice T (1982) Specific impairments of planning. Philosophical Transactions of the Royal Society of London, B, 199-209.

Sharpe MH (1990a) Distractibility in early Parkinson's disease. Cortex, 26, 239-246.

Sharpe MH (1990b) Patients with early Parkinson's disease are not impaired on spatial orientating of attention. Cortex, 26, 515-524.

Sharpe MH (1992) Auditory attention in early Parkinson's disease: An impairment in focused attention. Neuropsychologia, 30, 101-106.
Smith ML and Milner B (1981) The role of the right hippocampus in the recall of spatial location. Neuropsychologia, 19 , 781-793.

Smith ML and Milner B (1989) Right hippocampal impairment in the recall of spatial location: Encoding deficit or rapid forgetting? Neuropsychologia, 27, 71-81.

SPSS/PC + (1989) Logistic Regression Analysis, Version 3.1, Ch. 6, pp. B-81-107. SPSS International B.V., The Netherlands.

Starkstein SE, Preziosi TJ, Berthier ML, Bolduc PL, Mayberg HS and Robinson RG (1989) Depression and cognitive impairment in Parkinson's disease. Brain, 112, 1141-1153.

Stelmach GE, Phillips JG and Chau AW (1989) Visuospatial processing in Parkinsonians. Neuropsychologia, 27, 485-493.

Stern Y, Mayeux R and Rosen J (1984) Contribution of perceptual motor dysfunction to construction and tracing disturbances in Parkinson's disease. Journal of Neurology, Neurosurgery, and Psychiatry, 47, 983-989.

Taylor AE, Saint-Cyr JA and Lang AE (1986) Frontal lobe dysfunction in Parkinson's disease: The cortical focus of neostriatal outflow. Brain, 109, 845-883.

Testa D, Fetoni V, Soliveri P, Musico M, Palazzini E and Girotti $\mathrm{F}$ (1993) Cognitive and motor performance in multiple system atrophy and Parkinson's disease compared. Neuropsychologia, 31, 207-210.

Villardita C, Smirni P and Zappala G (1983) Visual neglect in Parkinson's disease. Archives of Neurology, 40, 737-739.

Wallesch C-W, Karnath HO, Papagno C, Zimmerman P, Deuschl G and Lucking CH (1990) Parkinson's disease patient's behaviour in a covered maze learning task. Neuropsychologia, 8, 839-849.

Wechsler D (1955) Wechsler Adult Intelligence Scale. Psychological Corporation, New York.

(Received 21 September 1993; accepted 10 October 1993) 


\section{APPENDIX}

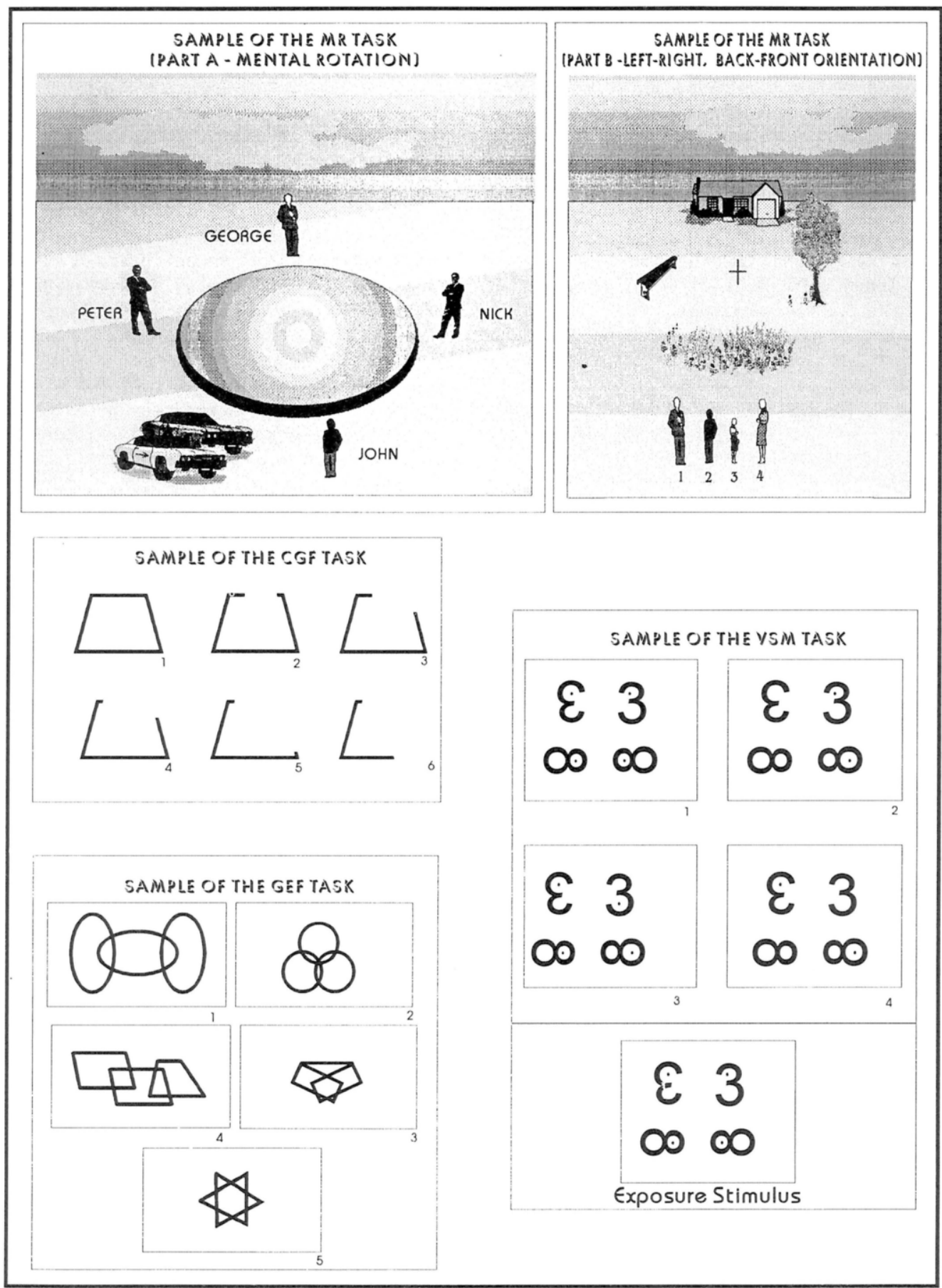




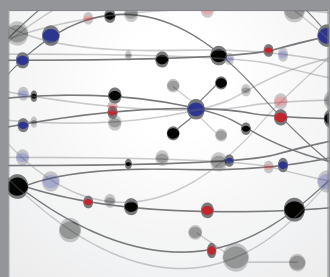

The Scientific World Journal
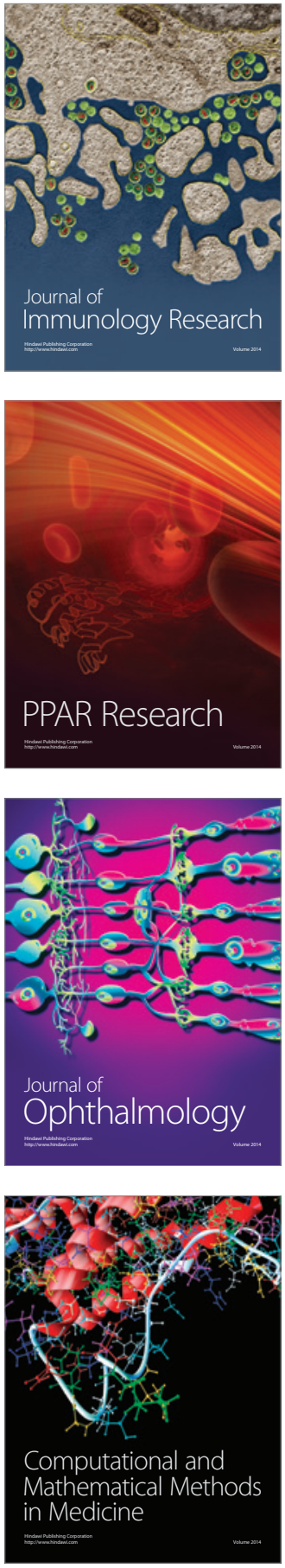

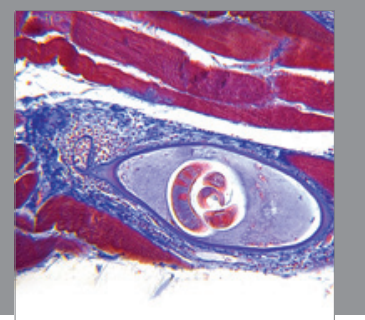

Gastroenterology

Research and Practice
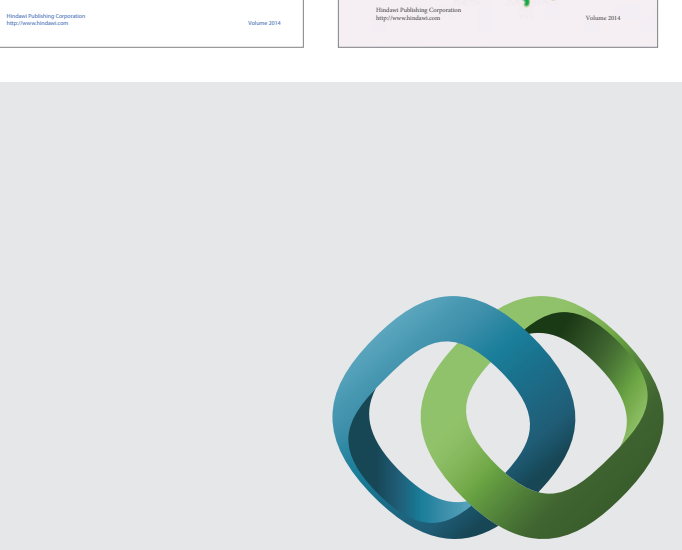

\section{Hindawi}

Submit your manuscripts at

http://www.hindawi.com
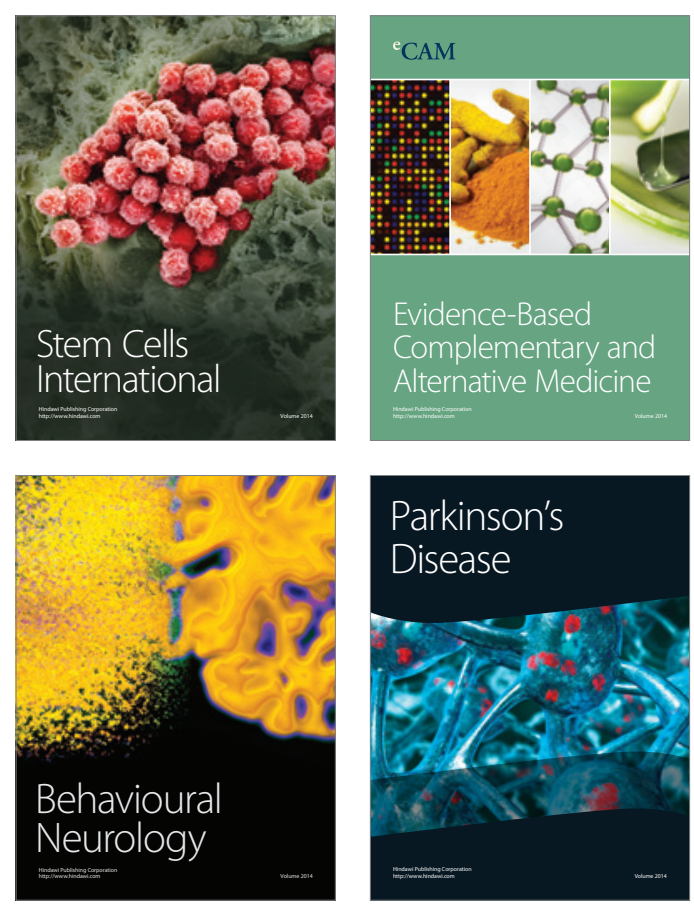

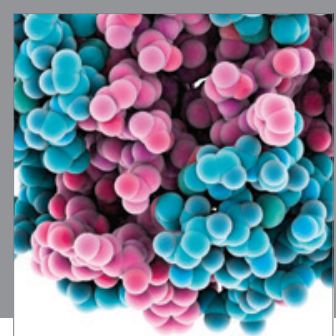

Journal of
Diabetes Research

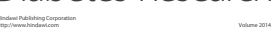

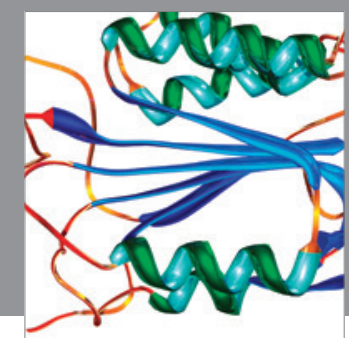

Disease Markers
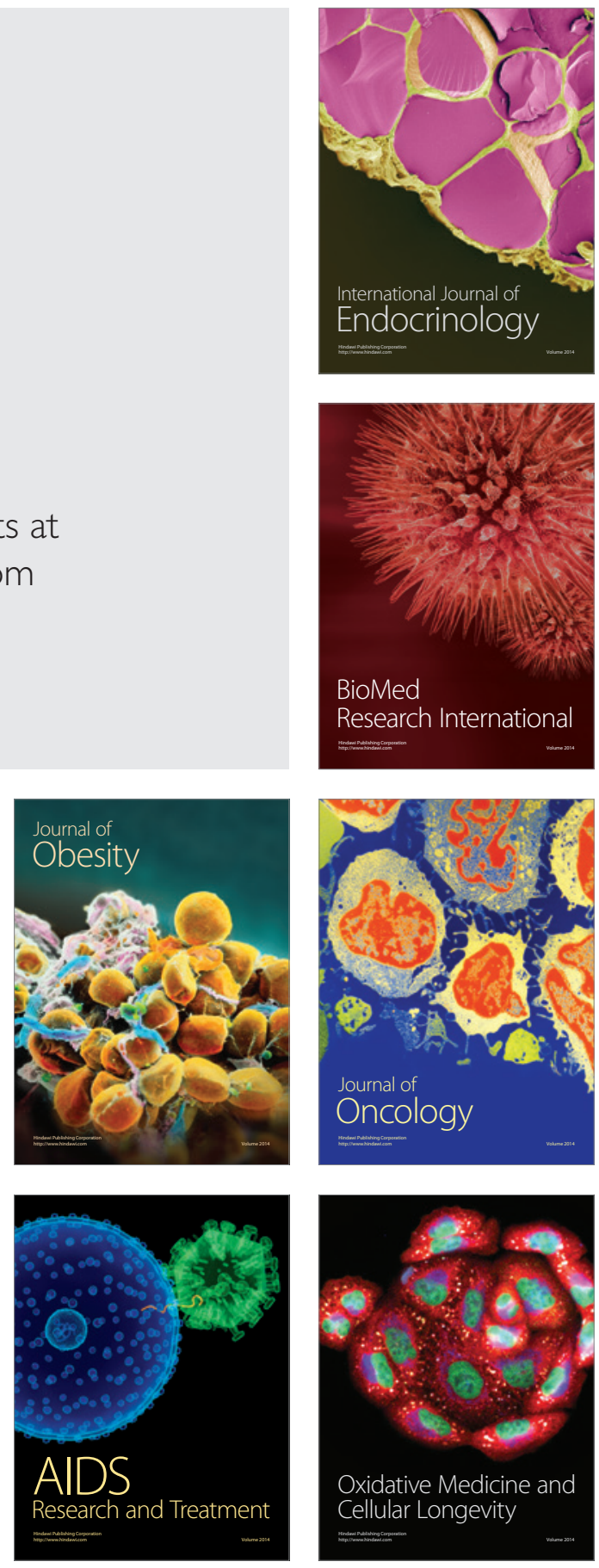